\title{
Dementia in Canadian primary health care: The potential role of case management
}

\author{
Vladimir Khanassov, Pierre Pluye, and Isabelle Vedel
}

\section{McGill University}

Dementia is a chronic disease characterized by progressive memory loss and behavioural disturbance. It has become a major concern for healthcare professionals due to the increasing number of people affected, usually presenting with more than one chronic condition. ${ }^{1}$ According to the World Health Organization (WHO), up to eight million new cases of dementia are detected world-wide annually. ${ }^{2}$ Today in Canada, half a million people are living with dementia and this number is expected to rise two and a half times over the next 40 years due to an aging population. ${ }^{3}$ The WHO has declared dementia to be one of the most serious health challenges facing our society due to its pronounced consequences on patients, their families and society. ${ }^{2}$ Various elements contribute to this quandary including patient-caregiver dyad factors (e.g., fear of stigmatization) and healthcare system issues (e.g., fragmentation of healthcare services). In this article we discuss Case Management (CM) designed for patients with dementia, and types of $\mathrm{CM}$ pertinent to primary care.

\section{Dementia and primary care: The current situation}

The first contact people with dementia have in the healthcare system is with a Family Physician (FP). The FP is thus ideally positioned to address their needs. Despite the fact that four Canadian consensus conferences on dementia have recommended FPs to be in charge of the prevention, diagnosis, and care for persons with dementia, ${ }^{4}$ FPs are reluctant to deal with these patients due to a lack of knowledge and confidence in using cognitive screening tests, and poorly coordinated primary and secondary care services. ${ }^{5}$ Unlike most European countries, Canada does not have a national plan on dementia partly due to the fact that healthcare is a provincial responsibility. To address this challenge, the provinces of Quebec and Ontario have developed dementia collaborative care models in the context of a major primary care reform that integrates personalized dementia service delivery within
Family Medicine Groups (Quebec) and Family Health Teams (Ontario). ${ }^{6,7}$

One of the key innovative interventions of these models is CM. ${ }^{6,7} \mathrm{CM}$ is defined as a collaborative process in which a case manager assesses an individual's health, plans a care path, coordinates health services, and monitors health status. This intervention aims for the timely delivery of patient-centered, comprehensive, and inter-professional care throughout the course of the disease in primary care. A case manager works closely with FPs and can facilitate their workloads, allowing FPs to more effectively focus on care. Patients with complex issues are referred to specialists (e.g., memory clinics).

\section{Dementia case management: A potential solution?}

The results of studies on the effectiveness of dementia CM have shown that it has the potential to improve outcomes. ${ }^{8}$ A few systematic reviews have demonstrated the positive effect on clinical outcomes, service use, cost-effectiveness, and caregiver satisfaction. ${ }^{9}$ Varieties of $\mathrm{CM}$ models are described in the literature on disease management, including hospital and service-based models. However, it is not clear what types of $\mathrm{CM}$ models are pertinent to primary care as systematic reviews conducted to date combine all types of CM. ${ }^{9}$ For example, there are no studies comparing case managers working independently versus case managers working in collaboration with other healthcare professionals (FPs and/or specialists). An ideal combination appears to be a case manager working in collaboration with FPs: "an FP treats and a case manager organizes". There is also no agreement about the best combination of healthcare professionals to address the needs of patients with dementia. Some researchers do not consider the direct involvement of a physician and a multidisciplinary team to be essential for $\mathrm{CM}$ effectiveness. ${ }^{10}$ 
To identify which of the types of $\mathrm{CM}$ models is more effective in primary care, we conducted a systematic review of intervention studies and examined the differences in outcomes for the patient-caregiver dyad (Table 1).

The findings of our systematic review did not show a clear difference between the three types of dementia CM with respect to outcomes. For example, "case manager working independently" showed a more prominent effect on caregiver outcomes (e.g., burden), while "case manager - multidisciplinary team - FP collaboration" demonstrated effective management of dementia in terms of medication management and adherence to dementia guidelines. Better medication management was related to the improvement of neuropsychiatric symptoms of dementia.

\section{Conclusion: Future directions to be considered}

Dementia $\mathrm{CM}$ in primary care is a potential solution to improve the outcomes of the patient-caregiver dyad. While the outcomes of $\mathrm{CM}$ cannot be explained by the CM type only, the patient-caregiver dyad will benefit from the close collaboration of a case manager, FPs and a multidisciplinary team. This collaboration can provide a comprehensive approach to meet their needs (e.g., assessment of functional status of patients). However, $\mathrm{CM}$ should be carefully implemented for its successful adoption by FPs. High CM intensity (e.g., a small caseload, proactive versus reactive follow-up), and effective communication between healthcare professionals in primary care should be monitored. ${ }^{8}$

\begin{tabular}{|c|c|}
\hline & Stages of the systematic review \\
\hline Stage 1. Definition of & f research question \\
\hline Question & With regard to patients with dementia in primary care, what type of $\mathrm{CM}$ is more effective? \\
\hline Stage 2. Definition of & f eligibility criteria \\
\hline Inclusion criteria & $\begin{array}{l}\text { Population: people of any age and gender with any type of dementia. Setting: CM intervention implemented in a range of } \\
\text { community settings. Types of interventions: CM interventions that comprise assessment, coordination, monitoring, and } \\
\text { delivery of services to meet patients' needs. Type of studies: intervention studies assessing outcomes of CM (e.g., randomized } \\
\text { controlled trial - RCT). Types of outcome measures: clinical outcomes (e.g., neuropsychiatric symptoms), service use (e.g., } \\
\text { nursing home admission), caregiver outcomes (e.g., depression), satisfaction, cost-effectiveness, and other outcomes. }\end{array}$ \\
\hline Stage 3. Developmer & th of an extensive search strategy \\
\hline Databases & Publications listed in MEDLINE, PsycInfo, EMBASE, the Cochrane Database. \\
\hline Timeframe & Between 1995 (official publication of the CM Standards of Practice) and 2012. \\
\hline Language & English and French \\
\hline Stage 4. Identificatio & $\mathrm{n}$ of relevant studies and selection of the data \\
\hline $\begin{array}{l}\text { Identification of } \\
\text { the studies }\end{array}$ & $\begin{array}{l}\text { Titles and abstracts were selected independently by two reviewers (VK, IV). Then, full text copies were examined for final } \\
\text { inclusion. Kappa scores were calculated to estimate inter-reviewer reliability. }\end{array}$ \\
\hline Stage 5. Appraisal of & the quality of included studies \\
\hline Quality assessment & The validated Mixed Methods Appraisal Tool was used. Inter-rater reliability was calculated based on weighted kappa. \\
\hline Stage 6. Synthesis of & included studies \\
\hline Synthesis approach & $\begin{array}{l}\text { A narrative synthesis approach was used. A meta-analysis was not possible due to the heterogeneity of CM implementation. To } \\
\text { evaluate the magnitude of the positive outcomes we calculated the effect size using the Cohen method. }\end{array}$ \\
\hline Results & \\
\hline Types of CM & $\begin{array}{l}\text { Based on the composition of health care professionals, three types of CM were identified: case manager working independently, } \\
\text { case manager-multidisciplinary team collaboration, and case manager- multidisciplinary team-FP collaboration }\end{array}$ \\
\hline $\begin{array}{l}\text { Characteristics of } \\
\text { the types }\end{array}$ & $\begin{array}{l}\text { Case manager working independently: primarily focused on support of the patient-caregiver dyad; strictly applies the } \\
\text { traditional tasks of case manager; no interaction with physicians on a regular basis. Case manager-multidisciplinary team } \\
\text { collaboration: case manager acts as a liaison between different healthcare professionals (FP, geriatrician); FP is not involved in } \\
\text { the care. Case manager-multidisciplinary team-FP collaboration: FP is a key element of a strong partnership; case manager has } \\
\text { regular contact with FP of patients and their caregivers. }\end{array}$ \\
\hline Outcomes & $\begin{array}{l}\text { Case manager working independently: caregiver burden (effect size: } 0.5 \text { ) and mood (effect size: } 0.41 \text { ). Case manager- } \\
\text { multidisciplinary team collaboration: behavioral symptoms of dementia (effect size: } 1.5 \text { ) and caregiver mood (effect size: } 1.5 \text { ). } \\
\text { Case manager- multidisciplinary team-FP collaboration: medication management (e.g., rate of anticholinesterase prescription } \\
\text { by FPs) (effect size: } 1.07 \text { ) and adherence to dementia guidelines (effect size: } 0.65 \text { ). }\end{array}$ \\
\hline
\end{tabular}




\section{References}

1. Schubert CC, Boustani M, Callahan CM, Perkins AJ, Carney CP, Fox C, et al. Comorbidity profile of dementia patients in primary care: are they sicker? J Am Geriatr Soc. 2006;54(1):104-9.

2. WHO. Dementia A Public Health Priority. World Health Organization 2012

3. Alzheimer society of Canada. Rising Tide: The impact of Dementia on Canadian Society. 2010.

4. Troisième conférence canadienne de consensus sur le diagnostic et le traitement de la démence: Recommandations approuvées. 2007.

5. Aminzadeh F, Molnar FJ, Dalziel WB, Ayotte D. A review of barriers and enablers to diagnosis and management of persons with dementia in primary care. Canadian geriatrics journal : CGJ. 2012;15(3):85-94.
6. Lee L, Kasperski MJ, Weston WW. Building capacity for dementia care: training program to develop primary care memory clinics. Can Fam Physician. 2011;57(7):e249 52.

7. Bergman H. Report of the Committee of Experts for the Development of an Action Plan on Alzheimer's Disease and Related Disorders. 2009.

8. Khanassov V, Vedel I, Pluye P, Bergman H. Case management for patients with dementia in primary care: Why it doesn't work-A mixed studies systematic review. Alzheimers Dement. 2013;9(4):116.

9. Pimouguet $\mathrm{C}$, Lavaud T, Dartigues JF, Helmer C. Dementia case management effectiveness on health care costs and resource utilization: a systematic review of randomized controlled trials. J Nutr Health Aging. 2010;14(8):669-76.

10. Verkade P, van Meijel B, Brink C, van Os-Medendorp H, Koekkoek B, Francke A. Delphi research exploring essential components and preconditions for case management in people with dementia. BMC Geriatr. 2010;10:54.
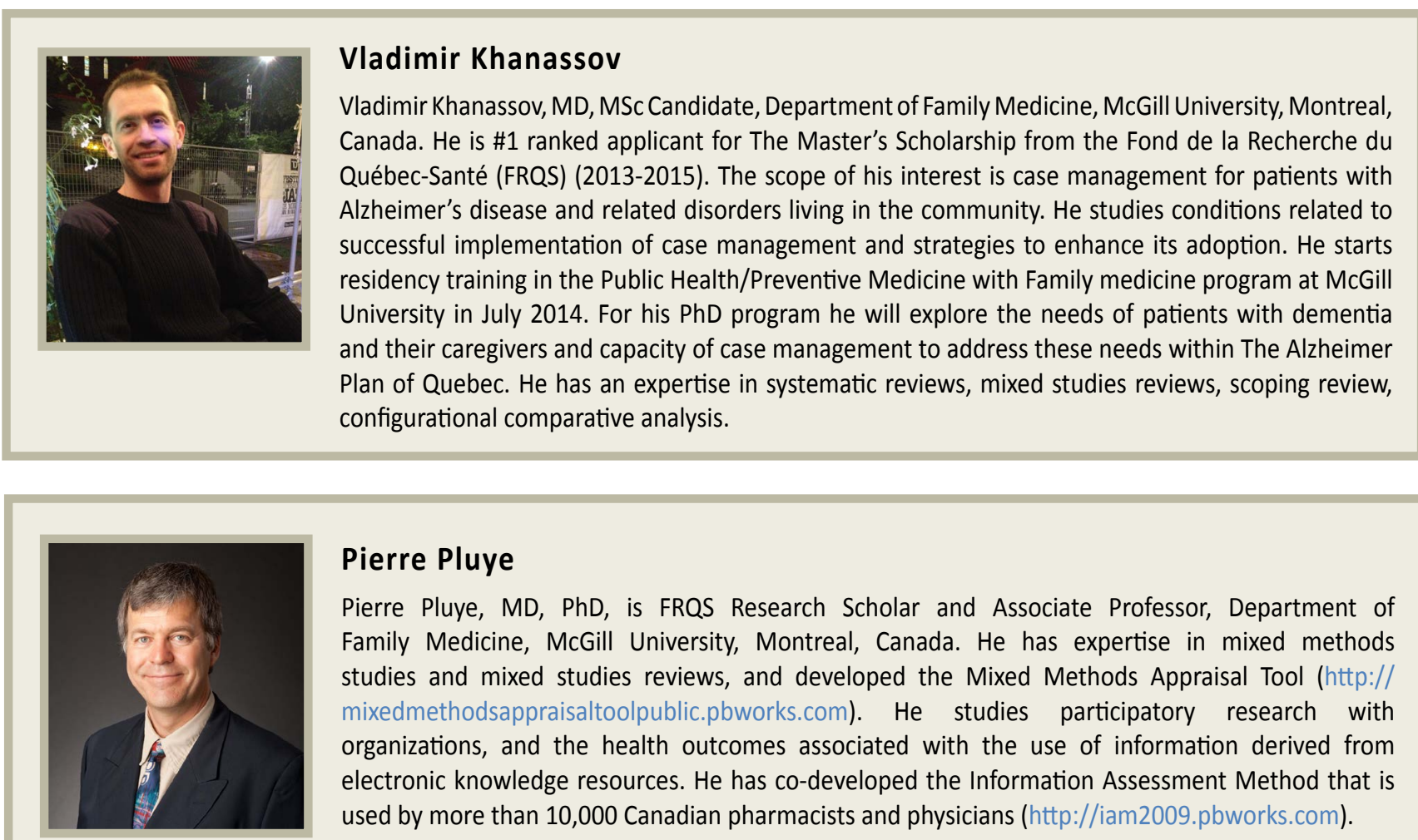

\section{Pierre Pluye}

Pierre Pluye, MD, PhD, is FRQS Research Scholar and Associate Professor, Department of Family Medicine, McGill University, Montreal, Canada. He has expertise in mixed methods studies and mixed studies reviews, and developed the Mixed Methods Appraisal Tool (http:// mixedmethodsappraisaltoolpublic.pbworks.com). He studies participatory research with organizations, and the health outcomes associated with the use of information derived from electronic knowledge resources. He has co-developed the Information Assessment Method that is used by more than 10,000 Canadian pharmacists and physicians (http://iam2009.pbworks.com).

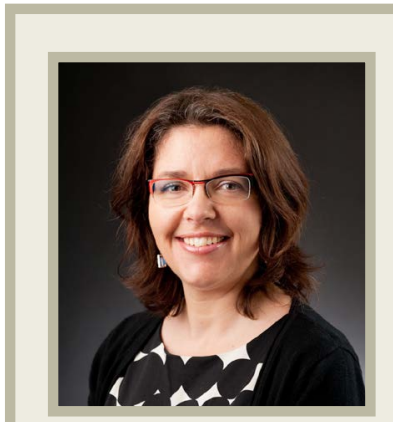

\section{Isabelle Vedel}

Isabelle Vedel. MD, PhD, public health physician and an Assistant Professor in the Department of Family Medicine and at the Division of Geriatrics, McGill University. Her research interests are mainly in health care organization and primary health care services for persons with multiple chronic diseases and older patients. Her research work focuses on health services research in chronic disease management, particularly Alzheimer's or related disorders. Dr. Vedel is presently conducting studies on the implementation and impacts of new models of primary care, such as integrated care services and transitional care for complex patients with multiple chronic diseases including Alzheimer's or related diseases. Dr. Isabelle Vedel is also undertaking research studies on the implementation of health information technologies in the context of chronic disease management. 